\title{
Asymmetric Return and Volatility Responses to Composite News from Stock Markets
}

\author{
Thomas C. Chiang \\ Drexel University, U.S.A. \\ Cathy W.S. Chen \\ Feng Chia University, Taiwan \\ Mike K.P. So \\ The Hong Kong University of Science and Technology, China
}

This paper examines the hypothesis that both stock returns and volatility are asymmetric functions of past information derived from domestic and U.S. stock-market news. The results show the presence of negative autocorrelation, which is consistent with the dominance of positive-feedback trading behavior. By employing a double-threshold autoregressive GARCH model to investigate four major index-return series, the study finds significant evidence to sustain the asymmetric hypothesis of stock returns. Specifically, this paper finds that negative news will cause a decline in national stock returns that is larger than the gain caused by good news of an equivalent magnitude. This also holds true for the conditional variance. The return appears to be more volatile and persistent when bad news hits the market than when good news does (JEL: C15, C22, G12).

Keywords: asymmetry, threshold GARCH, volatility, Bayesian estimation, posterior-odds ratio.

\section{Introduction}

Recent empirical studies of national stock-index returns have noted several empirical regularities. First, daily stock returns typically have

* The authors would like to thank our anonymous reviewers, Yin-Wong Cheung, Peter Theodossiou, C.W.J. Granger, Wessel Marquering, Michael J. Gombola, Shu-Chyi Doong, C.W. Li, W.K. Li, and participants in the meeting of the European Financial Association at Humboldt University, 2002, for their useful comments and suggestions. Thomas C. Chiang would like to acknowledge the research support received from the Marshall M. Austin fund, Drexel University.

(Multinational Finance Journal, 2007, vol. 11, no. 3/4, pp. 179-210)

(C) by Multinational Finance Society, a nonprofit corporation. All rights reserved. DOI: $10.17578 / 11-3 / 4-2$ 
exhibited autocorrelation attributable to nonsynchronous trading, time-varying short-term expected returns, costs of price adjustments, and interactions of positive and negative feedback traders. Scholes and Williams (1977), Lo and MacKinlay (1990), Fama and French (1988), Amihud and Mendelson (1987), Damodaran, (1993), Koutmos (1998), Sentana and Wadhwani (1992), and Antoniou, Koutmos, and Pericli (2005) provide supportive evidence for each argument. Second, national stock returns are significantly correlated, and linkages among international stock markets have grown more interdependent over time. In their multi-country analyses of cross correlations of national stock returns, Hamao, Masulis, and Ng (1989), Koutmos and Booth (1995), Kim and Rogers (1995), Chiang (1998), and Chen, Chiang, and So (2003) all find significant evidence of cross-market spillovers, in both stock returns and volatilities.

In conducting empirical analyses of stock-market spillover, ARCH-type models (Engle [1982], Bollerslev [1986], French, Schwert and Stambaugh [1987], Schwert [1989], Pagan and Schwert [1990], Lin, Engle and Ito [1994], Baillie and DeGennaro [1990], and Cheung and Westermann [2001]) have been widely used for their capacity to model clustering phenomena of stock-return volatility. Bollerslev, Chou, and Kroner (1992) conclude that the GARCH $(1,1)$ model appears to be sufficient to describe the volatility evolution of a stock-return series.

A drawback of standard ARCH-type models is that the estimated coefficients are assumed to be fixed throughout the sample period and fail to take into account the asymmetric effect between positive and negative shocks to stock returns. This leads to the third regularity: an asymmetric effect is found in studying stock-return series. It has been shown that a negative shock to stock returns will generate greater volatility than a positive shock of equal magnitude. By extending the research methods proposed by Nelson (1991), significant evidence to support the asymmetric hypothesis of stock-index returns is found by Glosten, Jagannathan, and Runkle (1993), Engle and Ng (1993), and Koutmos (1997, 1998, and 1999), among others. More recently, Bekaert and Wu (2000) and Wu (2001) use Japan's Nikkei 225 stock index to highlight the leverage effect and volatility feedback effect in explaining asymmetric volatility in response to news.

In tackling the autocorrelation and asymmetric phenomenon, Amihud and Mendelson (1987), Damodaran (1993), and Koutmos (1998) propose partial-adjustment price models by arguing that prevailing stock prices incorporate negative returns faster than they do positive returns. Thus, the 
news variable is implicitly embedded in the autoregressive process of the mean equation. Alternatively, Sentana and Wadhwani (1992) and Antoniou, Koutmos, and Pericli (2005) emphasize the relative market strength of the feedback between positive and negative traders: dominance of positive-feedback traders leads to negatively autocorrelated stock returns, while governance of negative-feedback traders produces positively autocorrelated stock returns. ${ }^{1}$

It is argued further that positive-feedback trading dominates at levels of high volatility, while negative-feedback trading dominates at levels of low volatility. As such, positive-feedback trading causes negative autocorrelation, which rises, in absolute terms, with the level of volatility. Asymmetric effect in this model reflects the market phenomenon that the magnitude of negative autocorrelation due to a large decline in price (bad news) increases more than its decline, in absolute measure, with an equivalent increase in price (good news).

The models proposed by Amihud and Mendelson (1987), Damodaran (1993), and Koutmos (1998) are useful and appropriate if our interest is to focus on examining whether news of negative returns is incorporated into current prices faster than news reflecting positive returns. It is also appealing to use the models suggested by Sentana and Wadhwani (1992) and Antoniou, Koutmos, and Pericli (2005) if we want to highlight trading strategies by investigating investor decisions based on domestic past-price movements. Their models, however, exclude very important information: cross-market correlation/feedback. ${ }^{2}$

In viewing the bulk of the evidence cited earlier, that returns are internationally correlated (Hamao, Masulis, and Ng [1989], King and Wadhwani [1990], Bae and Karolyi [1994], Koutmos and Booth [1995]) and that innovations in the U.S. market are transmitted rapidly to the rest of the world (Eun and Shim [1989], Masih and Masih [2001]), it is of interest to examine whether stock returns in the advanced capital markets also react asymmetrically to news from the U.S. stock market.

1. Positive (negative) feedback traders buy stocks after prices rise (fall) and sell after prices fall (rise) and thereby destabilize (stabilize) stock markets.

2. In examining nine developed stock-market indices, Koutmos (1998) presents a model to investigate asymmetric effects and finds that asymmetries in the conditional mean are linked to asymmetries in the conditional variance, since the faster adjustment of prices to negative returns gives rise to higher volatility during down markets. Bekaert and Wu's model (2000) also presents a unified framework for examining asymmetric volatility in response to news at the firm level and at the domestic market level. However, their models do not explicitly distinguish domestic versus foreign stock news. 
The decision to include the U.S. market as part of the information set is based on several factors. First, the causality tests (see Appendix A1), both Granger and Sims tests, show consistently that causal relationships have been dominated by information running from the U.S. market to international markets, although a minor feedback is found in the case of the Japanese market. Second, the U.S. market, with its dominant trading position in world capital markets, is also the most influential producer of information. Its technological advances and computerized trading systems have greatly facilitated the transfer of information flows from market to market. Third, empirical evidence presented by Masih and Masih (2001) confirms earlier findings (Eun and Shim [1989]) that the U.S. market provides price leadership in the world marketplace. Fourth, international investors often overreact to news from the U.S. market and are less sensitive to other markets (Becker, Finnerty, and Friedman [1995]). Therefore, stock news released from the U.S. market is expected to be transmitted to other markets in an efficient way.

From an econometric point of view, instead of simply extending a TAR model (Tsay [2001a]), AR-EGARCH model (Koutmos [1999]), or EAR-TGARCH model (Koutmos [1997]) by emphasizing an autocorrelation specification based on domestic stock-return news, we specify a mean equation by linking current return to a news index containing past information from both domestic and U.S. markets. Moreover, the interest here is in examining the possibility of asymmetric effects in reactions to the news index, in both return and volatility. To capture these features, a double-threshold-autoregression GARCH model (DTR-GARCH) is proposed, with the model being estimated by a Bayesian method. On the basis of Bayesian estimations, we derive optimal market-return index news to project future stock returns for each market.

This study differs from previous research in several respects. First, instead of focusing exclusively on single-stock information embodied in the autocorrelation term (Sentana and Wadhwani [1992], Koutmos, [1997, 1998], Tsay [2001a]) or cross-market information (Chen, Chiang, and So [2003]), this paper employs composite news derived from both domestic and foreign markets and analyzes the asymmetries in returns and variances. This specification allows us to examine individual news effects or combinations from both stock sources. Thus, these findings will provide a broader avenue for processing past information in a multi-asset framework and will shed light on the asymmetric effect of international stock returns. Second, a Bayesian method will be used in 
an empirical estimation to generate a vector of unknown parameters, $\Theta$, in the DTR-GARCH model, including a threshold value, $r$; an optimal weight, $w$; and a time delay, $d$. This allows us to generate approximated samples from the posterior distribution of $\Theta$ via a Markov chain Monte Carlo (MCMC) method (Chib and Greenberg [1995], Tsay [2001b)]. Thus, the usual restriction by pre-setting $r$ and $d$ in estimating a threshold model can be avoided.

Following this introduction, the remainder of the paper is structured as follows. Section II describes the data and presents some statistical properties of stock returns in a standard GARCH $(1,1)$ specification. Section III provides the rationale and procedures for using a Bayesian estimation of a DTR-GARCH model. Section IV presents the estimated results for both mean and conditional variance equations by using the Bayesian method and includes a discussion of model checking and selection. Section V contains concluding remarks.

\section{The Data and Basic Statistics}

\section{A. Data Sample}

The data used in this study are daily stock-price indices for five stock markets for the period of January 1, 1990, through April 15, 2005. The data consist of the Toronto SE 300 (Canada), the FTSE 100 (United Kingdom), the Dax 30 (Germany), the Nikkei 225 (Japan), and the S\&P 500 (United States). All the data were taken from Data Stream International. Following the conventional approach, taking the natural logarithmic difference of the daily stock index times 100 generates the daily stock-return series. That is, $R_{t}=100\left(p_{t}-p_{t-1}\right)$, where $p_{t}$ and $p_{t-1}$ are the natural logarithms of a stock index at time $t$ and $t-1$.

The investigation covers the major stock indices in the global marketplace, those of Canada, the United Kingdom, Germany, Japan, and the United States. This wide array of data allows us to investigate market behavior involving spatial differentials, which may be unique or country specific. Comparing the realized returns for stock indices in a given calendar day in different real-time periods is not an easy job. Stock markets in different countries operate in different time zones with different opening and closing times. To address this issue, Kofman and Martens (1997), Kahya (1997), and Martens and Poon (2001) construct synchronous data to analyze correlation and instant market behavior. 


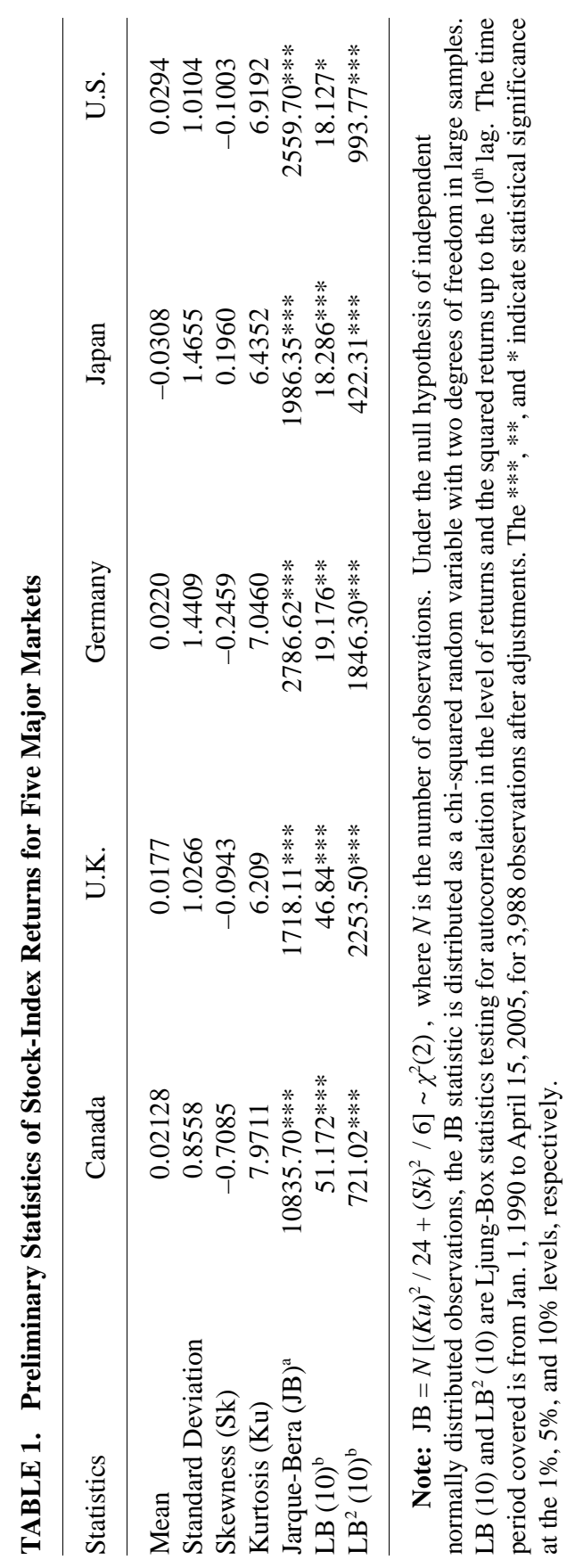


Yet, investors may not react to news instantaneously due to fear of market uncertainty, liquidity constraints, and time required to reformulate investment strategies. In practice, risk-averse investors tend to take time to reassess their investment performance based on daily market-index movements and then to restructure their portfolios. Consequently, the most recent closing price plays a vital role in assisting investors in that portfolio structuring and hence influences the following-day price movements. Moreover, stock trading at New York City (the S\&P 500 Index in the U.S. market) is the last market to close among the different world exchanges under investigation. So closing news in the U.S. market at day $(t-1)$ will have sufficient time to be transmitted to the Japanese and various European markets, facilitating their investment decision-making processes.

\section{B. Basic Statistics}

To provide a general understanding of the nature of each market's return, a summary of basic statistics of the daily returns is reported in Table 1. The statistics contain mean, standard deviation, skewness (Sk), kurtosis $(\mathrm{Ku})$, and Ljung-Box tests. The mean values range from -0.0308 (Japan) to 0.0294 (United States) and the standard deviations from 0.8558 (Canada) to 1.4655 (Japan). In terms of mean-variance criterion, North American markets have exhibited better performance, followed by the European markets. The Japanese market appears to show a negative return as well as the highest standard deviation. The unfavorable performance of Japanese stock returns is attributable to the fact that the Japanese market has been experiencing a bear market since 1989, and this situation was further aggravated by the Asian crisis and the U.S. recession.

The statistics for skewness and excess kurtosis suggest that the data depart from normality. The normality test, as measured by the Jarque-Bera statistic, is rejected for all the markets. The rejection occurs because the stock-index changes are either not independent, not normally distributed, or both. Thus, we examine the independence of stock returns up to the $10^{\text {th }}$ order. On the basis of the Ljung-Box statistics, the measures of LB (10) are highly significant, rejecting the absence of autocorrelation in the daily data. The existence of autocorrelation may result from market frictions or slow adjustments. The $\mathrm{LB}^{2}(10)$ statistics for examining the null hypothesis of dependency on the squared returns are also significant, suggesting that the variance 
is presenting a clustering phenomenon. From the test results then, it may be argued that stock-index changes deviate from normality due either to leptokurtosis or to asymmetry.

\section{Causal Relationship}

It is important to note that stock markets in different countries operate in different time zones with different opening and closing times. The focal point of this study is not to investigate the impact of instantaneous stock news derived from high-frequency data, which can be highlighted by intra-day or tic-tac data. Rather, the intention here is simply to examine the effect of market closing information flowing from the U.S. market to other major trading markets. This is based to some extent on the fact that New York City market operations (the S\&P 500 Index) are the last to close among the global exchanges under investigation. Closing news in the U.S. market at day $(t-1)$ will have informational content that will provide sufficient time for investors in Japanese and European markets to analyze market momentum and formulate their optimal portfolio decisions in the following trading day. A priori, we anticipate that U.S. market news will have a more profound effect on Japanese and European markets than on the Canadian market, since both U.S. and Canadian markets close at the same time.

To provide statistical information to justify the causal sequence of the stock-return series, we conduct both the Granger test and the Sims test. The results are presented in Appendix A1. The $F$-statistics show consistently that causal relationships have been dominated by information running from the U.S. market to international markets, although a minor feedback is found from the Japanese market. In particular, no matter whether the U.S. stock-return variable is used to serve as an incremental variable in the Granger test or is being used to explain future stock-return variables for international markets in the Sims test, the null hypothesis of no causality is strongly rejected in all cases. We can conclude from the evidence, then, that U.S.-stock news plays a major role in explaining international stock returns.

\section{The Traditional Model}

Before getting into the empirical analysis, it is convenient to start with an estimation of a traditional model that can serve as a basis of comparison. It follows that the current stock return is specified as a 
TABLE 2. Estimates of Stock-Index Returns for the GARCH(1,1) Model

\begin{tabular}{|c|c|c|c|c|}
\hline Coefficient & Canada & U.K. & Germany & Japan \\
\hline \multicolumn{5}{|c|}{ A. Regression Estimates } \\
\hline$\varphi_{0}$ & $\begin{array}{l}0.032 * * * \\
(0.0100)\end{array}$ & $\begin{array}{l}0.0225^{* *} \\
(0.0122)\end{array}$ & $\begin{array}{l}0.0356^{* *} \\
(0.0170)\end{array}$ & $\begin{array}{c}-0.0123 * * \\
(0.0188)\end{array}$ \\
\hline$\varphi_{1}$ & $\begin{array}{l}0.1248^{* * * *} \\
(0.0124)\end{array}$ & $\begin{array}{l}-0.0992 * * * \\
(0.0166)\end{array}$ & $\begin{array}{l}-0.1175^{* * *} \\
(0.0173)\end{array}$ & $\begin{array}{l}-0.0485^{* * * *} \\
(0.0164)\end{array}$ \\
\hline$\psi_{1}$ & $\begin{array}{l}0.0677 * * * \\
(0.0142)\end{array}$ & $\begin{array}{l}0.3091 * * * \\
(0.0146)\end{array}$ & $\begin{array}{l}0.4611 \text { *** } \\
(0.0203)\end{array}$ & $\begin{array}{l}0.4283 * * * \\
(0.0166)\end{array}$ \\
\hline$\alpha_{0}$ & $\begin{array}{l}0.0063^{* * * *} \\
(0.0010)\end{array}$ & $\begin{array}{l}0.0104 * * * \\
(0.0023)\end{array}$ & $\begin{array}{l}0.0198 * * * \\
(0.0028)\end{array}$ & $\begin{array}{l}0.0428 * * * \\
(0.0045)\end{array}$ \\
\hline$\alpha_{1}$ & $\begin{array}{l}0.0775^{* * * *} \\
(0.0039)\end{array}$ & $\begin{array}{l}0.0074 * * * \\
(0.0060)\end{array}$ & $\begin{array}{l}0.0634 * * * \\
(0.0040)\end{array}$ & $\begin{array}{l}0.00868 * * * \\
(0.0064)\end{array}$ \\
\hline$\beta_{1}$ & $\begin{array}{l}0.9158 * * * \\
(0.0037)\end{array}$ & $\begin{array}{l}0.9148 * * * \\
(0.0073)\end{array}$ & $\begin{array}{l}0.9247 * * * \\
(0.0053)\end{array}$ & $\begin{array}{l}0.8935 * * * \\
(0.0072)\end{array}$ \\
\hline$\alpha_{0} /\left(1-\alpha_{1}-\beta_{1}\right)$ & 0.3738 & 0.9603 & 1.601 & 2.1622 \\
\hline LB (10) & 6.1100 & 14.2257 & 5.7486 & 4.3487 \\
\hline $\mathrm{LB}^{2}(10)$ & 3.3248 & 6.5124 & 0.9273 & 5.9120 \\
\hline \multicolumn{5}{|c|}{ B. Volatility Specification Tests } \\
\hline $\begin{array}{l}\text { Sign-Bias } \\
\text { ( } t \text {-ratio) }\end{array}$ & $\begin{array}{l}0.163^{* *} \\
(0.073)\end{array}$ & $\begin{array}{c}0.005 \\
(0.068)\end{array}$ & $\begin{array}{l}0.441^{* * * *} \\
(0.151)\end{array}$ & $\begin{array}{l}0.382 * * * \\
(0.141)\end{array}$ \\
\hline \multicolumn{5}{|l|}{ Negative Size } \\
\hline $\begin{array}{c}\text { Bias } \\
(t \text {-ratio })\end{array}$ & $\begin{array}{l}-0.611 * * * \\
(0.064)\end{array}$ & $\begin{array}{l}-0.498 * * * \\
(0.056)\end{array}$ & $\begin{array}{l}-0.976 * * * \\
(0.084)\end{array}$ & $\begin{array}{l}-0.645 * * * \\
(0.083)\end{array}$ \\
\hline \multicolumn{5}{|l|}{ Positive Size } \\
\hline $\begin{array}{r}\text { Bias } \\
(t \text {-test })\end{array}$ & $\begin{array}{l}0.230 * * * \\
(0.073)\end{array}$ & $\begin{array}{l}0.432 * * * \\
(0.057)\end{array}$ & $\begin{array}{l}0.427 * * * \\
(0.092)\end{array}$ & $\begin{array}{r}0.187 * * \\
(0.0083)\end{array}$ \\
\hline $\begin{array}{c}\text { Joint Test } \\
\left(\chi^{2}(3)\right)\end{array}$ & $127.76^{* * *}$ & $207.59 * * *$ & $207.83^{* * *}$ & $87.31 * * *$ \\
\hline
\end{tabular}

Note: The model is: $R_{t}^{i}=\varphi_{0}+\varphi_{1} R_{t-1}^{i}+\psi_{1} R_{t-1}^{i}+u_{t} ; h_{t}=\alpha_{0}+\alpha_{1} u_{t-1}^{2}+\beta_{1} h_{t-1}$. The $* * *, * *$, and $*$ indicate statistical significance at the $1 \%, 5 \%$, and $10 \%$ levels, respectively. The numbers in parentheses are standard errors. Test equations for sign bias are as follows: (i) Sign-bias test: $\hat{u}_{t}^{2}=a+b S_{t-1}^{-}+v_{t}$, where $a$ is an intercept; $S_{t-1}^{-}$, is an indicator dummy that takes the value of unity if $\hat{u}_{t}<0$ and zero otherwise; and $v_{t}$ is an i.i.d. error term. The test is based on the $t$-statistics on $S_{t-1}^{-}$. (ii) Negative size-bias test: $\hat{u}_{t}^{2}=a$ $+b S_{t-1}^{-} u_{t-1}+v_{t}$. This test examines the significance of $S_{t-1}^{-} u_{t-1}$ by using a $t$-statistic to detect the effect of negative innovations. (iii) Positive size-bias test: $\hat{u}_{t}^{2}=a+b_{3} S_{t-1}^{+} u_{t-1}$ $+v_{t}$, where $S_{t-1}^{+}=\left(1-S_{t-1}^{-}\right)$is the indicator with positive innovations. This test is used to examine the significance of $S_{t-1}^{+} u_{t-1}$ by utilizing a $t$-statistic to detect the possible bias associated with positive innovations. (iv) Joint test: $\hat{\mathrm{u}}_{t}^{2}=\mathrm{a}+b_{1} S_{\mathrm{t}-1}^{-}+b_{2} S_{t-1}^{-} u_{t-1}+b_{3} S_{t-}^{+}$ ${ }_{1} u_{t-1}+v_{t}$. A joint test statistic is formulated by calculating $T R^{2}$ from the regression, which will asymptotically follow a $\chi^{2}$ (3) distribution with 3 degrees of freedom, under the null of no asymmetric effects. Alternatively, one can perform an $F$-test to examine the joint significance of the three variables, $S_{t-1}^{-}, S_{t-1}^{-} u_{t-1}, S_{t-1}^{+} u_{t-1}$ and in the regression of (iv). 
function of an AR (1) term and a lagged cross-asset return in the mean equation. The AR (1) term denotes domestic stock-return news, and the lagged cross-asset return captures recent foreign (U.S.) stock-return news. By assuming that the conditional variance can parsimoniously be represented by a GARCH $(1,1)$ process, as popularized by Bollerslev, Chou, and Kroner (1992), we estimate model 1, consisting of equation 1 and equation 2 , as follows:

$$
\begin{gathered}
R_{t}^{i}=\varphi_{0}+\varphi_{1} R_{t-1}^{i}+\psi_{1} R_{t-1}^{j}+u_{t} \\
h_{t}=\alpha_{0}+\alpha_{1} u_{t-1}^{2}+\beta_{1} h_{t-1},
\end{gathered}
$$

where $R_{t}^{i}$ and $R_{t}^{j}$ are stock returns from countries $i(i=$ Canada, United Kingdom, Germany and Japan) and $j$ (the United States), respectively; $h_{t}$ is the conditional variance; $\varphi_{0}, \varphi_{1}, \psi_{1}, \alpha_{0}, \alpha_{1}$, and $\beta_{1}$ and are constant parameters; and $u_{t}$ is a random-error term, $u_{t}=\sqrt{h_{t}} \varepsilon_{t}, \varepsilon_{t} \sim N(0,1)$.

Estimates of equation 1 and equation 2 are presented in table 2 , which contains the parameters of $\left(\varphi_{0}, \varphi_{1}, \psi_{1}, \alpha_{0}, \alpha_{1}, \beta_{1}\right)$ and the corresponding standard errors. Consistent with the presence of positive-feedback trading (Sentana and Wadhwani [1992]), the coefficients of the AR(1) term for the U.K., German, and Japanese markets are negative and statistically significant. This coefficient, however, is positive for the Canadian market, which follows the argument of partial adjustment (Koutmos [1998]) or nonsynchronous trading (Lo and Mackinlay [1990]). With respect to the coefficients of U.S. returns, the estimated signs are all positive, ranging from 0.0677 to 0.4611 , with the Canadian coefficient posting the lowest value. By checking the performance of the regressors, the coefficient of the U.S.-index returns appears to play a more significant role than does the AR (1) term for U.K., German and Japanese markets. The exception again occurs for the Canadian market. One possible explanation for this exception is the fact that the closing hour of stock markets in the United States and Canada is the same. However, there is a significant lag in the global time sequence when looking at the United Kingdom, Germany and Japan due to time-zone differences, such that stock-return news will have more informational content in these markets. ${ }^{3}$ Evidently, the hypothesis of the independence

3. In our empirical estimation using a Bayesian method, the time lag of news arrival at markets will be determined by the data through empirical estimation. However, if the U.S. and 
of stock-index returns from the U.S. market is uniformly rejected. The significance of the lagged U.S. stock returns and AR (1) component contradicts the efficient-market hypothesis.

Checking the variance equation, we find that all the coefficients in the GARCH $(1,1)$ equations are statistically significant, indicating that stock-return volatilities are characterized by a heteroscedastic process. Note that the average variance, measured by $\alpha_{0} /\left(1-\alpha_{1}-\beta_{1}\right)$, shows that both the United Kingdom and Japan have significantly higher average variances than the other markets under study.

By examining the adequacy of the mean equation as well as the validity of the volatility equation for the series $\tilde{u}_{t}$ and $\tilde{u}_{t}^{2}$, respectively, where $\tilde{u}_{t}=\hat{u}_{t} / \sqrt{h_{t}}$, we calculate the Ljung-Box statistics of the standardized shocks and the squared standardized shocks, respectively, up to the $10^{\text {th }}$ lag; those statistics have been reduced significantly as compared with those shown in table 1 . The test results show that the model is adequate.

Note that the portmanteau test is unable to detect the presence of asymmetries in the conditional variance. For this reason, the diagnostics for asymmetry proposed by Engle and $\mathrm{Ng}$ (1993) is performed. The tenet of these tests is based on the presumption that if the residual squared series follows an i.i.d. process, it should be independent of positive and negative innovations. Panel B presents four tests for investigating asymmetry, including a sign-bias test ( $t$-test), negative sign-bias test $(t$-test $)$, positive size-bias $(t$-test $)$, and joint tests $\left(\chi^{2}\right.$-test $) .{ }^{4} \mathrm{~A}$ clear conclusion derived from these tests is that the hypothesis of symmetrical conditional variances in these markets is uniformly rejected.

In addition, even though the system in equation 1 and equation 2 provides a framework to describe daily asset-return behavior in a GARCH $(1,1)$ process, the estimated coefficients are fixed and fail to reflect the asymmetric responses of market news. In order to examine whether past stock news would produce asymmetric effects on the conditional mean and conditional variance, we construct a threshold-regression-GARCH (TR-GARCH) model characterizing regime switching, and this model will be presented next.

Japanese markets display a correlation in the data on the same calendar day, it will reflect a Japanese lead of approximately 17 hours in real time as noted by Koch and Koch (1991).

4. The test equations for these four tests and variable specifications are contained in the notes of table 2 . 


\section{The Double TR-GARCH Model}

\section{A. The Model Representation}

The quantitative model adopted here is similar to the one proposed by Chen, Chiang, and So (2003), which is a generalization of the threshold ARCH models proposed by Li and Lam (1995), Li and Li (1996), and Chen (1998) or a self-exciting threshold autoregressive model (SETAR) proposed by Tong and Lim (1980), Tong (1983, 1990), and Tsay (1998). This model is characterized by several nonlinear factors commonly observed in practice to capture the asymmetry in declining and rising patterns of a process. It uses piecewise linear models to obtain a better description of conditional mean and conditional volatility equations. To elucidate the explanation, this study elaborates model 1 in the previous section in two different ways. First, an asymmetric model of stock returns and variance is specified by considering a single threshold variable, a domestic stock return, which is called model 2. Next, we get into the heart of our study by introducing composite stock-return news as the threshold variables in model 3 . These two models are presented as follows:

Model 2: Double-threshold GARCH with domestic lagged information as threshold variable

$$
R_{t}^{i}=\left\{\begin{array}{lll}
\varphi_{0}^{(1)}+\varphi_{1}^{(1)} R_{t-d}^{i}+\psi_{1}^{(1)} R_{t-d}^{j}+u_{t}, & \text { if } & z_{t-d} \leq r \\
\varphi_{0}^{(2)}+\varphi_{1}^{(2)} R_{t-d}^{i}+\psi_{1}^{(2)} R_{t-d}^{j}+u_{t}, & \text { if } & z_{t-d}>r
\end{array}\right.
$$

The corresponding GARCH $(1,1)$ specifications for the conditional variances are given by:

$$
\begin{aligned}
& h_{t}=\left\{\begin{array}{lll}
\alpha_{0}^{(1)}+\alpha_{1}^{(1)} u_{t-1}^{2}+\beta_{1}^{(1)} h_{t-1} & \text { if } & z_{t-d} \leq r \\
\alpha_{0}^{(2)}+\alpha_{1}^{(2)} u_{t-1}^{2}+\beta_{1}^{(2)} h_{t-1} & \text { if } & z_{t-d}>r
\end{array}\right. \\
& u_{t}=\sqrt{h_{t}} \varepsilon_{t}, \varepsilon_{t} \sim t(v) \\
& z_{t-d}=R_{t-d}^{i}
\end{aligned}
$$


Model 3: Double-threshold GARCH with composite lagged information as a threshold variable:

$$
R_{t}^{i}=\left\{\begin{array}{lll}
\varphi_{0}^{(1)}+\varphi_{1}^{(1)} R_{t-d}^{i}+\psi_{1}^{(1)} R_{t-d}^{j}+u_{t}, & \text { if } & z_{t-d} \leq r \\
\varphi_{0}^{(2)}+\varphi_{1}^{(2)} R_{t-d}^{i}+\psi_{1}^{(2)} R_{t-d}^{j}+u_{t}, & \text { if } & z_{t-d}>r
\end{array}\right.
$$

The corresponding GARCH $(1,1)$ specifications for the conditional variances are given by:

$$
\begin{aligned}
& h_{t}=\left\{\begin{array}{lll}
\alpha_{0}^{(1)}+\alpha_{1}^{(1)} u_{t-1}^{2}+\beta_{1}^{(1)} h_{t-1} & \text { if } & z_{t-d} \leq r \\
\alpha_{0}^{(2)}+\alpha_{1}^{(2)} u_{t-1}^{2}+\beta_{1}^{(2)} h_{t-1} & \text { if } & z_{t-d}>r
\end{array}\right. \\
& u_{t}=\sqrt{h_{t}} \varepsilon_{t}, \varepsilon_{t} \sim t(v) \\
& z_{t-d}=w R_{t-d}^{i}+(1-w) R_{t-d}^{j}
\end{aligned}
$$

Equation 3 and equation 4 specify a two-regime model by using $z_{t-d}$ as an information variable at time $t$ with a $d$-period delay. As indicated by equation 5, past domestic stock-return news is considered as a primary variable in model 2 to serve as an information variable. The superscript 1 indicates regime 1 , where the stock return is equal to or smaller than the critical value, $r$; otherwise, regime 2 corresponds to the state where the stock return is greater than $r$. As mentioned earlier, the national stock-index return is assumed to have an autoregressive term, $R_{t-d}^{i}$, that exhibits a partial adjustment of past price to its market fundamentals (Amihud and Mendelson [1987], Damodaran [1993], Koutmos [1998], Bekaert and $\mathrm{Wu}$ [2000]) or reflects a dominant positive-feedback trading behavior (Sentana and Wadhwani [1992]). ${ }^{5}$

A shortcoming of model 2 is that it fails to incorporate cross-market feedback into the information set. To highlight the significance of

5. If the stock indices follow a random-walk process, the stock returns reflect random news. In this way, $R_{t}^{i}=p_{t}^{i}-p_{t-1}^{i}=\varepsilon_{t}^{i}$ and $R_{t}^{j}=p_{t}^{j}-p_{t-1}^{j}=\varepsilon_{t}^{j}\left(p_{t}^{i}\right.$ and $p_{t}^{j}$ are stock indexes for country $i$ and $j$, expressed in natural logarithm), where $R_{t}^{i}$ and $R_{t}^{j}$ are domestic and foreign stock-return news, respectively. However, if stock returns (changes of stock prices) exhibit a partial adjustment toward the market fundamental price, $p_{t}^{f}$, and the latter follows a random walk with a drift, then the return series will follow an autoregressive process (see Koutmos [1999]). Alternatively, a dominant positive-feedback trading in the Sentana and Wadhwani (1992) model implies a negative autocorrelation. 
stock-return news from global markets due to correlations of the industrial structure (Roll [1992]), contagion effects (King and Wadhwani [1990]), or other forms of spillover (Ito, Engle and Lin [1992]), we add $R_{t-d}^{j}$ to $z_{t-d}$ to form a new information variable. With the dominant share of the U.S. market, which is also the last market to close on the global clock for a given calendar day, the foreign information $R_{t-d}^{j}$ in the context here is based mainly on U.S. stock-index return news. Thus, the threshold variable $z_{t-d}$ in equation 8 is a weighted average of country ith (domestic) lagged stock return and country $j^{\text {th }}$ market information (the lagged U.S. stock return), where $w$ in equation 8 is the weight of the country $i^{\text {th }}$ (domestic) market and follows the restriction that $w \in[0,1]$.

The time lag for news to arrive in national markets is expected to be relatively short from an efficient market point of view. Additionally, the parsimonious principle suggests that the lag length should be based on model fitting of available data without using any unnecessary parameters. The decision for the choice of the delay variable, $d$, in this study will depend on empirical regularity via data simulation, which is the mode in this empirical estimation. Again, the information variable is used to divide the test equation into two regimes as in model 2. Putting equations 6 through 8 together forms model 3 .

In sum, the dynamic structure of the mean equation depends on an autocorrelation term and on past U.S. stock-return news, and the variance equation follows a GARCH $(1,1)$ process by restrictions that $\alpha_{0}^{(i)}>0, \alpha_{1}^{(i)}, \beta_{1}^{(i)} \geq 0$ and $\left(\alpha_{1}^{(1)}+\beta_{1}^{(i)}\right)<1$, for $i=1$, 2. We fit a standardized Student-t distribution to capture empirical leptokurtosis (Andersen et al. [2000]). The model is divided into two different regimes in response to bad news, $z_{t-d} \leq r$, which we define as regime 1 , and good news, $z_{t-d}>r$, which we label regime 2 , to capture the mean and volatility asymmetries.

\section{B. Estimation Procedures}

Classical estimation of parameters in the threshold class of models is usually done by a least-squares method with $r, w$, and $d$ pre-fixed (Tong [1990]). Estimates of $r$ and $d$ are determined by using information criteria such as AIC and BIC (Tsay [1998], Shen and Chiang [1999]); $w$ is pre-set by either 0 or 1 . The shortcoming of this sampling approach is that by fixing $r, w$, and $d$ in advance, before estimating other parameters by least squares, the uncertainty of $r, w$, and $d$ cannot be taken into account when performing statistical inference for other parameters. 
To alleviate the problems arising from predetermining $r, w$, and $d$, a Bayesian approach is adopted, which allows us to estimate $r$ (threshold value), $w$ (weight parameter), $d$ (delay variable), and other parameters, such as $\left(\varphi_{0}^{(1)}, \varphi_{1}^{(1)}, \psi_{1}^{(1)}, \alpha_{0}^{(1)}, \alpha_{1}^{(1)}, \beta_{1}^{(1)}, \varphi_{0}^{(2)}, \varphi_{1}^{(2)}, \psi_{1}^{2}, \alpha_{0}^{(2)}, \alpha_{1}^{(2)}\right.$, $\left.\beta_{1}^{(2)}\right)$, simultaneously. That is, we can generate approximated samples from the posterior distribution of unknown parameters, including $\varphi_{0}^{(1)}$, $\varphi_{1}^{(1)}, \psi_{1}^{(1)}, \alpha_{0}^{(1)}, \alpha_{1}^{(1)}, \beta_{1}^{(1)}, \varphi_{0}^{(2)}, \varphi_{1}^{(2)}, \psi_{1}^{2}, \alpha_{0}^{(2)}, \alpha_{1}^{(2)}, \beta_{1}^{(2)}, r, w$, and $d$ via MCMC methods (Chib and Greenberg [1995], Chen [1998], Tsay [2001b], Chen, Chiang and So [2003], Chen and So [2006]). ${ }^{6}$ The estimation procedures of a Bayesian method are presented in Appendix A2.

\section{Estimated Results from a Bayesian Method}

Estimates of parameters for stock returns from double-threshold GARCH models using domestic lagged-return news and composite stock-return news, respectively, as a threshold variable are reported in table 3 and table 4 . In general, both models yield very similar qualitative results. Since model 3 is more general and appears to have more informational content, the analysis shall concentrate on the report of model 3 as shown in table 4 .

The estimated parameters reported in tables 4 are the values of the posterior means, while the numbers in parentheses are the corresponding posterior standard deviations of the parameters. As may be seen from table 4 , all of the $\varphi_{1}^{(i)} s(i=1,2)$ are negative and their values are sufficiently large as compared with the corresponding standard errors, indicating that the estimated parameters are highly significant at standard significance levels and consistent with the presence of positive-feedback trading (Sentana and Wadhwani [1992]). ${ }^{7}$

6. In standard sampling theory, the estimator and statistical inference are obtained and the true value of the parameter located in certain confidence intervals. The shortcoming of this method is that the confidence can be defined for certain restricted sets of intervals only. This restriction would not occur in the Bayesian method, since we can define a density function over the parameter space and thereby consider the probability in which a parameter lies. In the Bayesian approach, the posterior distribution provides a probability distribution over the parameter space obtained from the sample as well as from the a priori information (Amemiya [1994]). The discussion of Bayesian analysis and its comparison with sampling theory can be found in Greene (2000, pp. 402-412).

7. The results here are slightly different from those presented in a previous version of this paper (Chiang, Chen and So [2002]), since the data sample is advanced to April 15, 2005. The current results indicate that there are more negative correlations. Moreover, the weight placed on the U.S. stock returns has declined. 


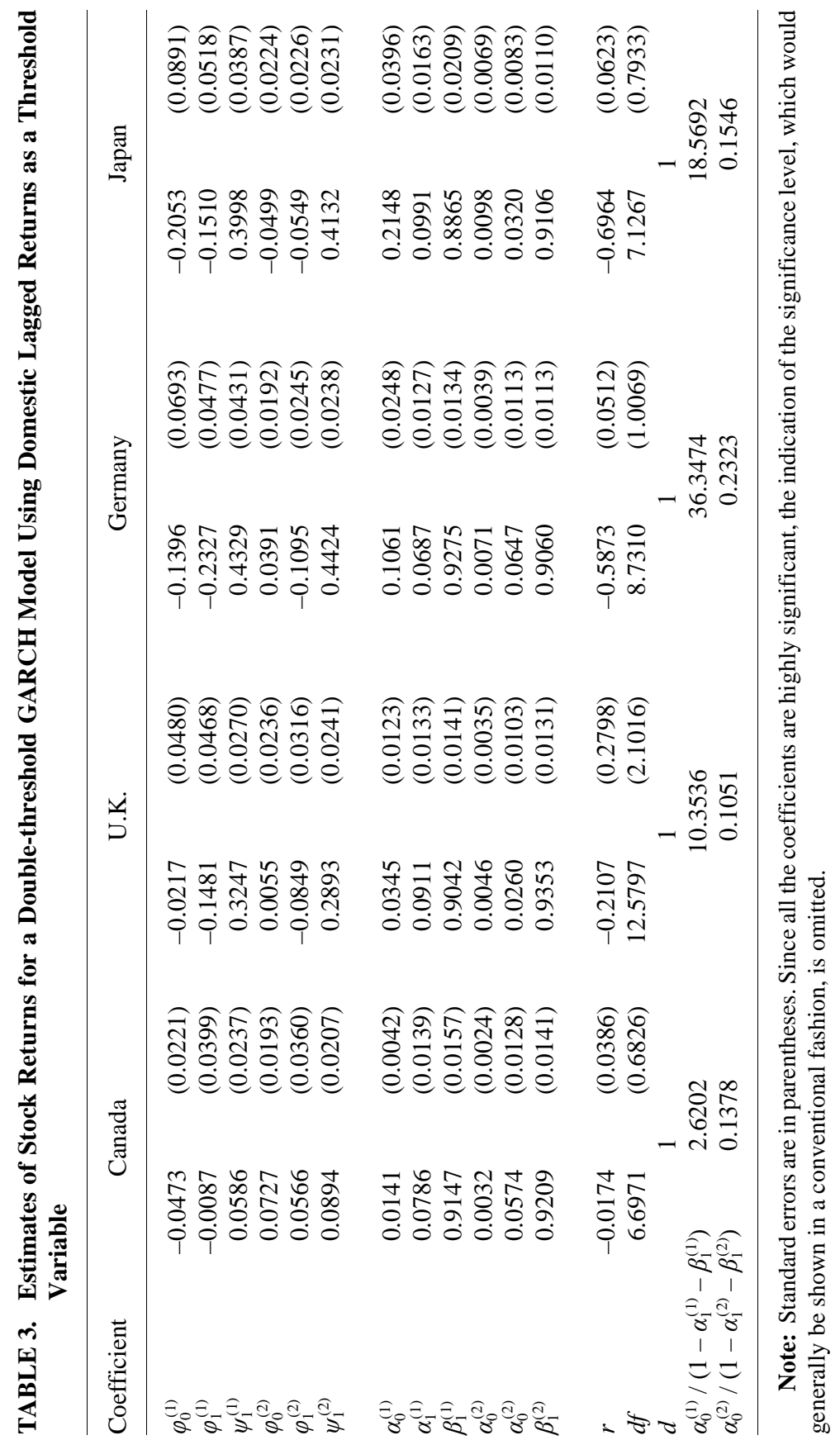




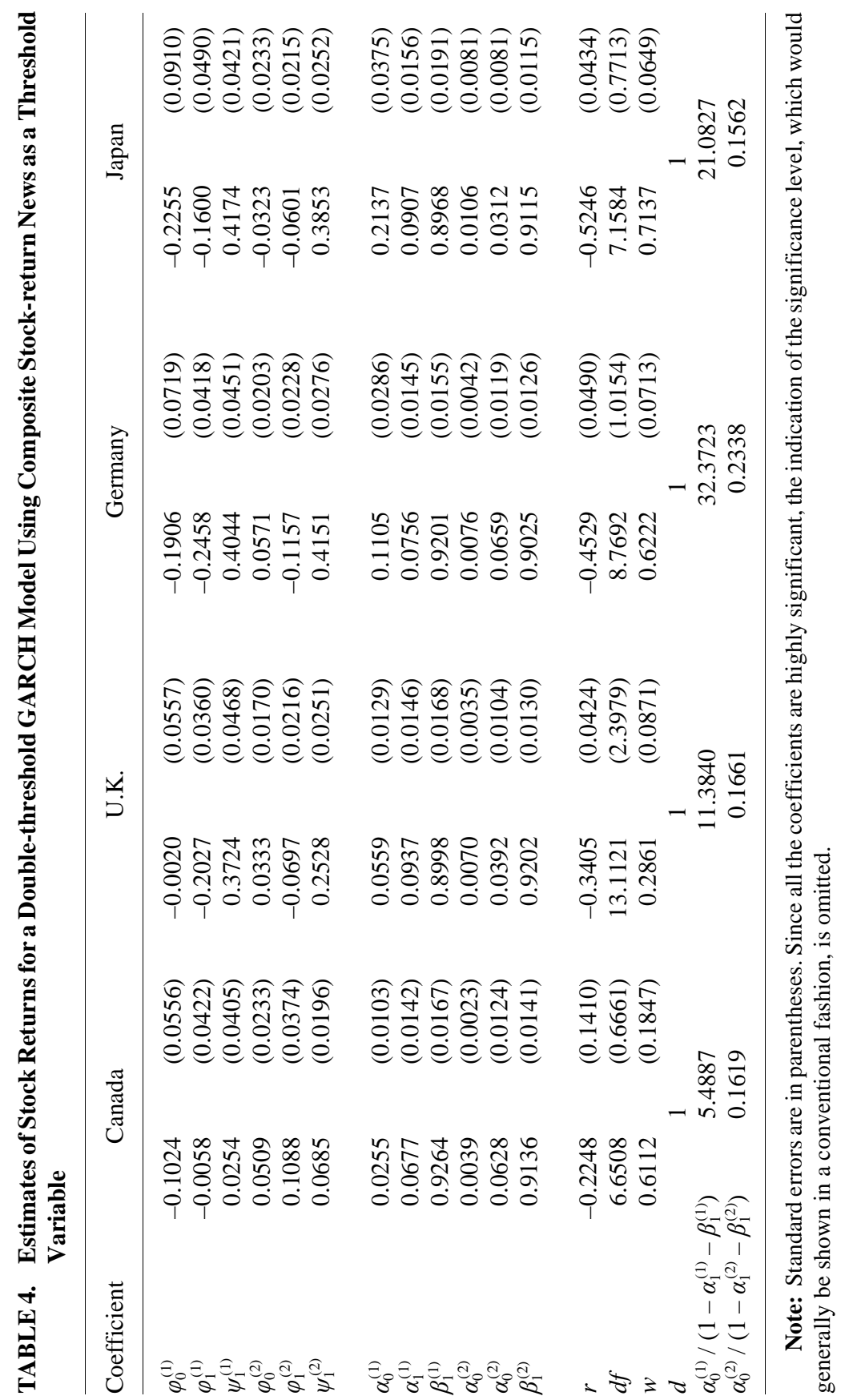


The only exception is the Canadian market where the AR (1) term is positive, especially in the good news regime. The presence of a positive sign may be due to the fact that both U.S. and Canadian markets, closing at the same time, share some common information. With respect to the coefficients of $\varphi_{1}^{(i)}$, all of them are positive and highly significant except for the Canadian market in a bad-news regime. In general, the evidence suggests that national stock returns are not independent of news released from the latest home and U.S. stock returns. ${ }^{8}$

Table 4 also reports the threshold variable, $r$, for each market. ${ }^{9}$ The evidence suggests that a loss produced by weighting the average of domestic and U.S. stock-index returns is considered to be bad news only it exceeds the threshold level. The findings show that the threshold values are in the ranges of -0.224 to -0.5246 and vary from market to market. ${ }^{10}$ The optimal weights derived from the MCMC sampling are $0.2861,0.6112,0.6222$, and 0.7137 for the United Kingdom, Canada, Germany, and Japan, respectively. These statistics suggest that market participants in the United Kingdom tend to place a relatively greater weight on U.S. stock-return news in projecting their stock returns, while investors in the other three markets place more weight on their domestic stock-return news. The most appropriate time delay that investors employ to assess market conditions is one day, which is shown in the $d$ values (the third row from the bottom) derived from the posterior modes. ${ }^{11}$

8. The world index excluding European market returns, $R_{t-d}^{\text {WI XER }}$, is used to serve as a foreign variable in the mean equation and an information variable to substitute for U.S. stock returns. That is, $z_{t-d}=w R_{t-d}^{i}+(1-\mathrm{w}) R_{t-d}^{W I X E R}$. The model appears to be "inadequate" for the United Kingdom, Japan, and Germany. For this reason, those results are not reported. The model with a linear combination of lagged domestic stock-return news and lagged U.S. stock-return news as the threshold variable is preferable.

9. In the threshold model, $r=0$ is not automatically used as a benchmark to define the gain or loss of stock investments. Rather, the threshold is searched to divide the process into two different structures, conditional on the time-series property.

10. It is possible to present multiple regimes with different threshold values. In particular, when the number of changes (regimes) is known, the MCMC method can be applied in a straightforward manner. However, in practice, it is not easy to decide the number of regimes having a particular economic meaning. Moreover, the computation can be very cumbersome. In this study, dividing the data into two regimes allows us to focus on the asymmetric phenomenon, which is the main concern in this paper.

11. LeBaron (1992) and Koutmos (1998) specify only one lag for the autoregressive parameter. Baillie and DeGennaro (1990) find a longer lag in the autocorrelation parameter. The optimal lag length in our model is searched out through our sampling process. In all of the cases, one lag is sufficient to capture the information. 


\section{A. Asymmetry in Stock Returns}

As shown in table 4, the Bayesian analysis of each stock-index return exhibits different behavior in reacting to stock news. The estimated mean coefficients and their corresponding standard errors obtained from regime 1 (bad news) are in general larger in magnitude than those appearing in regime 2 (good news), displaying asymmetric effects in the different regimes. The sign of the parameter $\varphi_{1}^{(1)}$ is negative and statistically significant. The estimated values of $\varphi_{1}^{(1)}$ are greater than those of $\varphi_{1}^{(2)}$ (in absolute value), indicating that the response of stock returns to past information is more sensitive in regime 1 (bad news) than in regime 2 (good news). Market participants in the United Kingdom, Germany, and Japan appear to exhibit consistent behavior: the sign of autocorrelation is negative whether good or bad news occurs. The performance of these markets is consistent with the dominance of positive-feedback traders. However, results show that the Canadian market exhibits sign reversals, indicating a phenomenon dominated by negative-feedback traders when good news occurs. Deviation of market behavior associated with the Canadian stock market versus other markets may be due to the fact that both U.S. and Canadian markets are more highly integrated and operate in the same time zone. The sharing of common market information tends to create co-movements and to generate positive coefficients for both $\varphi_{1}^{(2)}$ and $\psi_{1}^{(2)}$.

The asymmetric effect derived from U.S. stock-return news is not so noticeable. That of the U.K. market is more apparent, since it places more weight on U.S. stock-return news to project its stock movements, while the other three countries put less weight on the U.S. market. An important implication of identifying the weights in this study is that the information derived from table 4 can be a significant input for helping financial managers to differentiate the informational impact on stock returns and hence to manage their portfolios in response to different types of shocks.

\section{B. Estimation Results for Variance Equation}

The statistical performance shown in table 4 also indicates that conditional variance equations are well represented by a $\operatorname{GARCH}(1,1)$ process as evidenced by the high level of significance of the estimated coefficients, supporting the phenomenon of volatility clustering. In addition to this standard outcome, two significant findings are worth noting. First, an asymmetric effect is present in the variance equations. 
This can be seen from the constant component of the variance $\alpha_{0}^{(1)}$ versus $\alpha_{0}^{(2)}$. The estimated values for $\alpha_{0}^{(1)}$ are all higher than those of $\alpha_{0}^{(1)}$. In addition, the values of the average of the unconditional variance in regime $1, \alpha_{0}^{(1)} /\left(1-\alpha_{1}^{(1)}-\beta_{1}^{(1)}\right)$, are much larger than those in regime 2 , $\alpha_{0}^{(2)} /\left(1-\alpha_{1}^{(2)}-\beta_{1}^{(2)}\right)$, exhibiting an asymmetric reaction of stock volatility to negative news versus positive news.

This finding of asymmetric volatility is consistent with a number of results seen in the literature (Campbell and Hentschel [1992], Koutmos [1998], Bekaert and $\mathrm{Wu}$ [2000]). The underlying economic rationale is that whenever bad news affects the market, it creates fear and heightens stock volatility and it also triggers a large volume of selling. This higher level of volatility in the markets has to be compensated by higher expected returns, leading to a decline in stock prices. Owing to the very nature of volatility persistence, as implied by the $\operatorname{GARCH}(1,1)$ process, the conditional volatility is expected to be revised further upward due to market momentum. Moreover, the wealth effect due to implementation of stop-loss orders as emphasized by Black (1988) or the leverage effect triggered by price declines could reinforce the volatility acceleration as described by Bekaert and Wu (2000). As a result, we anticipate that a negative shock in stock markets could generate a substantial increase in conditional volatility. The activity of positive-feedback trading further reinforces the increase in negative autocorrelation. Note that when good news enters the market, it generates an enthusiasm that stimulates market volatility as a result of an increase in orders. However, this increase in volatility will be moderated by price declines caused by demand for a higher expected return. At the same time, the leverage effect is also likely to exhibit downward pressure on the conditional volatility. Thus, positive news does not necessarily create a significant increase in conditional volatility. Putting these two stories together, it is clear that the effect on conditional volatility is more profound when bad news hits the market than when good news does.

Second, the sum of the estimated coefficients, $\left(\alpha_{1}^{(1)}+\beta_{1}^{(1)}\right)$, is close to unity, and $\left(\alpha_{1}^{(2)}+\beta_{1}^{(2)}\right)$ is not, implying that $\left(\alpha_{1}^{(1)}+\beta_{1}^{(1)}\right)>\left(\alpha_{1}^{(2)}+\beta_{1}^{(2)}\right)$ and that the volatility in regime 1 maintains a higher persistence, or a longer memory. This suggests that bad news tends to create a longer negative effect than does good news, which is consistent with investor behavior in which experiencing a loss in the stock market creates a more persistent fear than does momentary gain and the excitement derived from a positive stock return. 


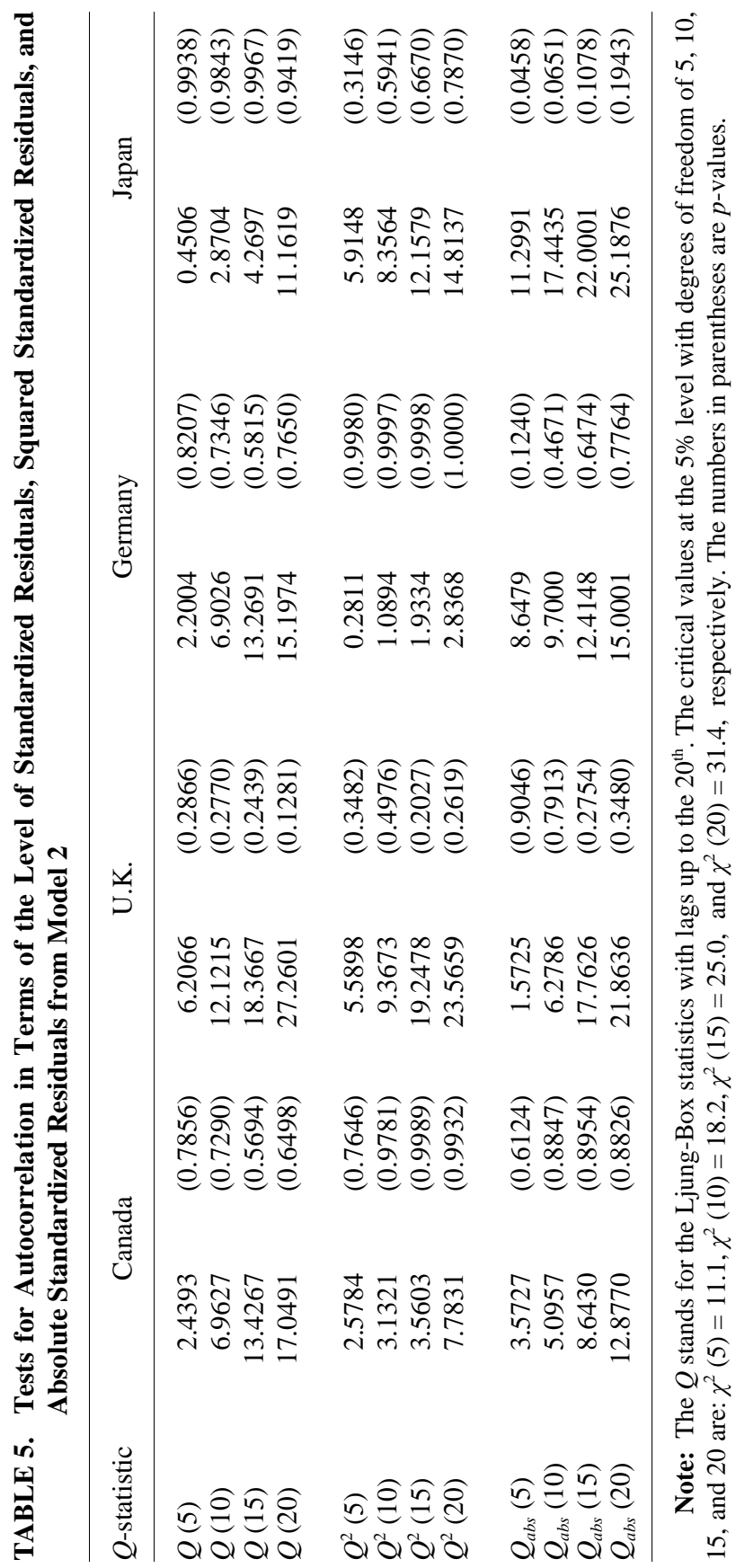




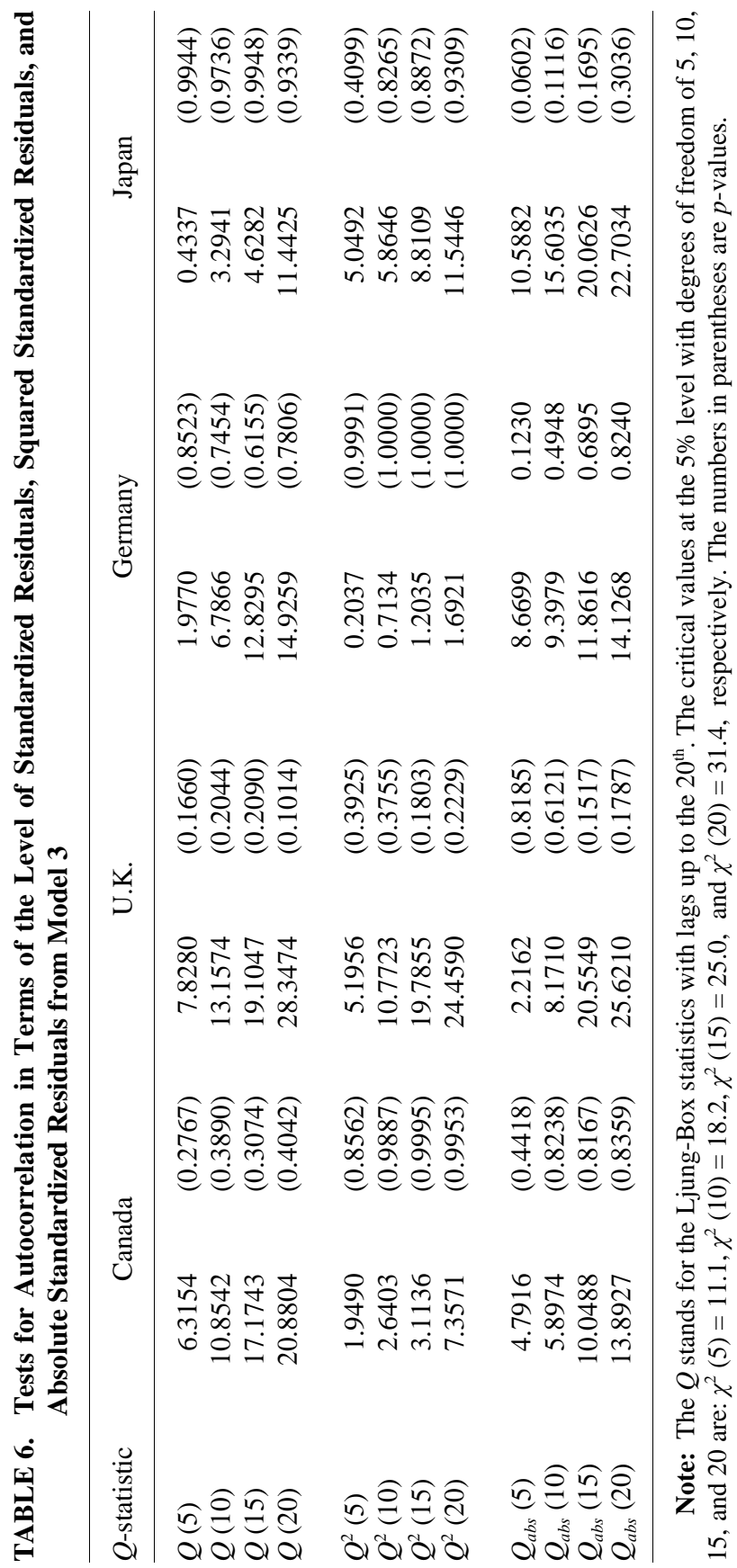




\section{Model Checking and Selection}

To examine the performance of the models, we conduct the diagnostic tests suggested by $\mathrm{Li}$ and $\mathrm{Li}$ (1996) to the standardized residuals derived from the double TR-GARCH models. The tests apply to Q-statistics in calculating the joint significance of autocorrelations in the standardized residuals, squared standardized residuals, and absolute standardized residuals up to the $20^{\text {th }} \mathrm{lag}$. The test results are reported in table 5 (for model 2) and table 6 (for model 3), respectively. Comparing these estimated statistics with the critical values of $\chi^{2}(d . f$.) with $d . f .=5,10$, 15 , and 20, none of the Q-statistics is significant. Evidently, both model 2 and model 3 are adequate.

To compare the performance between two competitive models, we use a Bayesian decision rule: the posterior-odds ratio (Zellner [1971]). For any two models, say $A$ and $B$, the posterior-odds ratio $\left(P O R_{A, B}\right)$ is given by:

$$
\operatorname{POR}_{A, B}=\frac{p(A \mid R)}{p(B \mid R)}=\frac{p(R \mid A) \operatorname{pr}(A)}{p(R \mid B) \operatorname{pr}(B)},
$$

where $\operatorname{pr}(A)$ and $\operatorname{pr}(B)$ are prior probability for models $A$ and $B$, respectively, and $\operatorname{pr}(A)$ represents the chance that $A$ is the true model before collecting data. It is subjectively chosen and is a probability based on prior belief, experience, or history. After collecting data, we have to revise $p(A)$ to the posterior probability that $A$ is the true model $p(A \mid R)$. Given the data information, $R$, in the sample, the conditional probability that $A$ is the true model will be $p(A \mid R)$. If $p(A \mid R)>$ $p(B \mid R), A$ is preferable to $B$ because $A$ has a higher chance of being true compared with $B$, given the data. The decision rule is to choose model $A$ if $P O R_{A, B}>1$; otherwise, choose model $B$. From equation 9, $P O R_{A, B}$ $>1$ implies that $p(A \mid R)>p(B \mid R)$, meaning that after observing the data, the probability of model $A$ being the true model is higher than that of model $B$.

The logarithmic posterior-odds ratios for three alternative models are reported in table 7, where we make pair-wise comparisons. Since all of the logarithmic posterior-odds ratios are greater than zero $\left(\ln \left[P O R_{A, B}\right]\right.$ $>0$ implies that $P O R_{A, B}>1$ ), we conclude that $A$ is preferable to $B$ when $A$ denotes model 3 - the threshold variable is defined as a weighted average of most recent domestic and U.S. stock-return news-and B stands for model 2-the threshold variable is based on the latest 
TABLE 7. Logarithm Posterior-odds Ratio

\begin{tabular}{lcccc}
\hline Models & Canada & Japan & Germany & U.K. \\
\hline M2 vs. $M 1$ & 86.4548 & 88.0358 & 113.6449 & 23.0324 \\
M3 vs. $M 1$ & 90.3249 & 91.0340 & 119.8309 & 27.8719 \\
M3 vs. $M 2$ & 3.8701 & 2.9982 & 6.1860 & 4.8396 \\
Model Selection & $M 3$ & $M 3$ & $M 3$ & M3 \\
\hline
\end{tabular}

Note: Model 1: Standard GARCH $(1,1)$ model $(M 1)$. Model 2: Double-threshold GARCH using domestic lagged information as threshold variable (M2). Consists of equation 3, equation 4 and equation 5. Model 3: Double-threshold GARCH using composite lagged information as a threshold variable (M3). Consists of equation 3, equation 4 , and equation 8 where $R_{t}^{i}$ and $R_{t}^{j}$ are stock returns from country $i$ ( $i$ : Canada, Germany, Japan, and the United Kingdom) and $j$ (the United States), respectively. For any two models, say $A$ and $B$, we employ the posterior-odds ratio $\left(P O R_{A, B}\right)$ given by equation 9 where $p(A \mid R)$ is the posterior probability that $A$ is the true model given the data information $R$ in the sample. A similar definition applies to $p(B \mid R)$. If $p(A \mid R)>$ $p(B \mid R), A$ is preferable to $B$ because $A$ has a higher chance of being true given the data, compared with $B$. The decision rule is to choose model $A$ if $P O R_{A, B}>1$; otherwise choose model $B$. Using the Canadian market as an example, $A$ denotes Model 3 , a double-threshold model with threshold variable: $z_{t-d}=\omega R_{t-d}^{i}+(1-\omega) R_{t-d}^{U S} ; B$ denotes Model 2, a double-threshold model with threshold variable: $z_{t-d}=R_{t-d}^{i}$. In our estimations, we obtain: $\ln \left(O R_{A B}\right)=3.8701$. Note that $\ln \left(P O R_{A B}\right)>0$ implies that $P O R_{A B}>1$, indicating that Model 3 is superior to Model 2.

domestic stock-return news. Apparently, both asymmetric models (model 2 and model 3 ) are superior to the naïve model (model 1). All in all, model 3 is the most preferable.

\section{Summary and Concluding Remarks}

This paper investigated the dynamic behavior of daily stock-index returns of four major stock markets. In conformance with well-established empirical regularities, the stock-index returns present some degree of persistence and have substantial international spillover; the volatility evolution process appears to be described well by a GARCH $(1,1)$ model. Since Engle and Ng (1993) tests for sign and size bias show that each stock-return series reveals strong asymmetric characteristics, a composite stock-return news variable is employed by weighting the average of the most recent domestic and U.S. stock-return 
news to specify a double-threshold GARCH model. ${ }^{12}$ The evidence from this model based on a Bayesian analysis shows that stock returns for the United Kingdom, Germany and Japan exhibit negative autocorrelation, while a positive sign of autocorrelation is present for the Canadian market. The evidence also suggests that all of the markets' returns are positively influenced by the U.S. stock-market news. In further analyzing the relative significance of stock news, the data suggest that the optimal weight, on average, is higher than 0.5 , meaning that, in forming the news index, a higher weight has been placed on domestic stock news for Canada, Germany, and Japan than on U.S. stock news. Here the exception is the United Kingdom, where lagged U.S. stock-return news carries more weight. By using a posterior-odds ratio, defined by the ratio of two posterior-model probabilities, to compare alternative models, the test results uniformly support the model specifying the threshold (news) variable by a weighted average of domestic and U.S. stock-return news.

This study shows consistently that asymmetric effects are present in both the mean equation and the conditional variance equation. The empirical results indicate that the estimated coefficients in both mean and variance equations are larger in the regime where bad news occurs in comparison with a regime of good news. In particular, price changes are more profound when bad news hits the market than when an equivalent amount of good news arrives. The values of unconditional variance in regime $1,\left(\alpha_{0}^{(1)} / 1-\alpha_{1}^{(1)}-\beta_{1}^{(1)}\right)$, are much larger than those in regime $2,\left(\alpha_{0}^{(2)} / 1-\alpha_{1}^{(2)}-\beta_{1}^{(2)}\right)$, for all markets, exhibiting an asymmetric reaction of stock volatility to negative news versus positive news. In a market dominated by positive-feedback traders, a higher volatility tends to further strengthen the negative autocorrelation. The evidence also suggests that the sum of the estimated coefficients for the variance equation in regime $1,\left(\alpha_{1}^{(1)}-\beta_{1}^{(1)}\right)$, is much closer to unity than the sum

12. Our notion differs from that suggested by Bekaert and Wu (2000), who argue that "negative unanticipated returns result in an upward revision of the conditional volatility, where positive unanticipated returns result in a smaller upward or even a downward revision of the conditional volatility" (see their equation 1). Their concern is to establish a link between volatility and domestic news in order to explain the asymmetry. This article, however, addresses the link between stock return and lagged news variables; the sources of the news are taken from both domestic and foreign markets. The model presented here is also at variance with Martens and Poon's model (2001) in that their focal point is on the correlation of returns through comparing synchronous versus synchronized data. Their model, however, places no emphasis on the asymmetry of the mean equation and stock-return dynamics. 
of coefficients in regime $2,\left(\alpha_{1}^{(2)}-\beta_{1}^{(2)}\right)$, implying that the volatility exhibits high persistence or has a longer memory when bad news hit the markets. This suggests that bad news tends to create a much longer negative effect than good news.

\section{References}

Amemiya, T. 1994. Introduction to Statistics and Econometrics. Cambridge, MA: Harvard University Press.

Amihud, Y., and Mendelson, H. 1987. Trading mechanisms and stock returns: An empirical investigation. Journal of Finance 42: 533-553.

Andersen,T. G..; Bollerslev, T.; Diebold, F. X.; and Labys, P. 2000. Exchange rate returns standardized by realized volatility are (nearly) Gaussian. Multinational Financial Journal 4: 159-179.

Antoniou, A.; Koutmos, G.; and Pericli, A. 2005. Index futures and positive feedback trading: Evidence from major stock exchanges. Journal of Empirical Finance 12: 219-238.

Bae, K., and Karolyi, G. A. 1994. Good news, bad news and international spillovers of stock return volatility between Japan and the U.S. Pacific-Basin Finance Journal 2: 405-438.

Baillie, R. T., and DeGennaro, R. P. 1990. Stock returns and volatility. Journal of Financial and Quantitative Analysis 25: 203-215.

Becker, K. G.; Finnerty, J. E.; and Friedman, J. E. 1995. Economic news and equity market linkages between the U.S. and U.K. Journal of Banking and Finance 19: 1191-1210.

Bekaert, G., and Wu, G. 2000. Asymmetric volatility and risk in equity markets. Review of Financial Studies 13: 1-42.

Black, F. 1988. An equilibrium model of the crash. NBER Macroeconomics Annual 269-276.

Bollerslev, T. 1986. Generalized autoregressive conditional heteroscedasticity. Journal of Econometrics 31: 307-327.

Bollerslev, T.; Chou, R. Y.; and Kroner, K. F. 1992. ARCH modeling in finance: A review of the theory and empirical evidence. Journal of Econometrics 52: 5-59.

Campbell, J. Y., and Hentschel, L. 1992. No news is good news: An asymmetric model of changing volatility in stock returns. Journal of Financial Economics 31: 281-318.

Chen, C. W. S. 1998. A Bayesian analysis of generalized threshold autoregressive models. Statistics and Probability Letters 40: 15-22.

Chen, C. W. S.; Chiang, T. C.; and So, M. K. P. 2003. Asymmetrical reactions to U.S. stock-return news: Evidence from major markets based on a double threshold model. Journal of Economics and Business 55: 487-502. 
Chen, C. W. S. and So, M. K. P. 2006. On a threshold heteroscedastic model. International Journal of Forecasting 22: 73-89.

Cheung, Y-C., and Ng, L. 1992. Stock price dynamics and firm size: An empirical investigation. Journal of Finance 47: 1885-1997.

Cheung Y-W., and Westermann, F. 2001. Equity price dynamics before and after the introduction of the Euro: A note. Multinational Financial Journal 5: $113-128$

Chiang, T. C. 1998. Stock returns and conditional variance-covariance: Evidence from Asian stock markets. In J. J. Choi and J. A. Doukas, (eds.), Emerging Capital Markets: Financial and Investment Issues. Westport, CT: Quorum Books.

Chiang, T. C.; Chen, C. W. S.; and So, M. K. P. 2002. Returns and volatility asymmetries in global stock markets. European Financial Association Meetings, Berlin, Germany, August 21-24.

Chib, S., and Greenberg, E. 1995. Markov chain Monte Carlo simulation methods in econometrics. Manuscript. St. Louis: Washington University, Olin School of Business.

Damodaran, A. 1993. A simple measure of price adjustment coefficients. Journal of Finance 48: 387-400.

Engle, R. F. 1982. Autoregressive conditional heteroskedasticity with estimates of the variance of U.K. inflation. Econometrica 50: 987-1008.

Engle, R.F., and Ng, V.K. 1993. Measuring and testing the impact of news on volatility. Journal of Finance 48: 1749-1778.

Eun, C. S., and Shim, S. 1989. International transmission of stock market movements. Journal of Financial and Quantitative Analysis 24: 241-256.

Fama, E.F., and French, F. 1988. Permanent and temporary components of stock prices. Journal of Political Economy 96: 246-273.

French, K.; Schwert, G. W.; and Stambaugh, R. 1987. Expected stock returns and volatility. Journal of Financial Economics 19: 3-29.

Gallant, R. A.; Rossi, P. E.; and Tauchen, G. 1992. Stock prices and volume. Review of Financial Studies 5: 199-242.

Glosten, L. R.; Jagannathan, R.; and Runkle, D. 1993. On the relation between the expected value and the volatility of the nominal excess return on stocks. Journal of Finance 48: 1779-1801.

Greene, W. H. 2000. Econometric Analysis. Upper Saddle River, NJ: Prentice-Hall.

Hamao, Y.; Masulis, R.; and Ng, V. 1989. Correlations in price changes and volatility across international stock markets. Review of Financial Studies 3: 281-307.

Ito, T.; Engle, R. F.; and Lin. W.-L. 1992. Where does the meteor shower come from? The role of stochastic policy coordination. Journal of International Economics 32: 221-240.

Kahya, E. 1997. Correlation of returns in non-contemporaneous markets. Multinational Financial Journal 1: 123-135. 
Kim, S. W., and Rogers, J. H. 1995. International stock price spillovers and market liberalization: Evidence from Korea, Japan, and the United States. Journal of Empirical Finance 2: 117-133.

King, M. A., and Wadhwani, S. 1990. Transmission of volatility between stock markets. Review of Financial Studies 3: 5-33.

Koch, P. D., and Koch, T. W. 1991. Evolution in dynamic linkages across daily national stock indexes. Journal of International Money and Finance 10: 231-251.

Kofman, P., and Martens, M. 1997. Interaction between stock markets: An analysis of the common trading hours at the London and New York stock exchange. Journal of International Money and Finance 16: 387-414.

Koutmos, G. 1997. Do emerging and developed stock markets behave alike? Evidence from six Pacific Basin stock markets. Journal of International Financial Markets, Institutions and Money 7: 221-234.

Koutmos, G. 1998. Asymmetries in the conditional mean and the conditional variance: Evidence from nine stock markets. Journal of Economics and Business 50: 277-290.

Koutmos, G. 1999. Asymmetric price and volatility adjustments in emerging Asian stock markets. Journal of Business Finance and Accounting 26: 83-101.

Koutmos, G., and Booth, G. G. 1995. Asymmetric volatility transmission in international stock markets. Journal of International Money and Finance 14: 747-762.

LeBaron, B. 1992. Sine relations between volatility and serial correlations in stock market returns. Journal of Business 65: 199-219.

Li, W. K., and Lam, K. 1995. Modeling asymmetry in stock returns by a threshold autoregressive conditional heteroskedastic model. Statistician 44: 333-341.

Li, C. W., and Li., W. K. 1996. On a double threshold autoregressive heteroscedasticity time series model. Journal of Applied Econometrics 11: 253-274.

Lin, W.-L.; Engle, R. F.; and Ito, T. 1994. Do bulls and bears move across borders? International transmission of stock returns and volatility. Review of Financial Studies 7: 507-538.

Lo, A. W., and MacKinlay, C. A. 1990. An econometric analysis of nonsynchronous trading. Journal of Econometrics 45: 181-211.

Masih, R., and Masih, A. M. M. 2001. Long and short term dynamic causal transmission amongst international stock markets. Journal of International Money and Finance 20: 563-587.

Martens, M., and Poon, S-H. 2001. Returns synchronization and daily correlation dynamics between international stock markets. Journal of Banking and Finance 25: 1805-1827.

Nelson, D. B. 1991. Conditional heteroskedasticity in asset returns: A new approach. Econometrica 59: 347-370. 
Pagan, A., and Schwert, G. 1990. Alternative models for common stock volatility. Journal of Econometrics 45: 267-290.

Roll, R. 1992. Industrial structure and the comparative behavior of international stock market indices. Journal of Finance 47: 3-42.

Scholes, M., and Williams, J. 1977. Estimating betas from non-synchronous data. Journal of Financial Economics 5: 309-327.

Schwert, G. W. 1989. Why does stock market volatility change over time? Journal of Finance 44: 1115-1153.

Sentana, E., and Wadhwani, S. 1992. Feedback traders and stock return autocorrelations: Evidence from a century of daily data. The Economic Journal 102: 415-435.

Shen, C. H., and Chiang, T. C. 1999. Retrieving the vanishing liquidity effect: A threshold vector autoregressive model. Journal of Economics and Business 51: 257-277.

Tong, H. 1983. Threshold Models in Nonlinear Time Series Analysis. New York: Springer-Verlag.

Tong, H. 1990. Non-linear Time Series: A Dynamical System Approach. Oxford: Oxford Science Publications.

Tong H., and Lim, K. S. 1980. Threshold autoregression, limit cycles and cyclical data (with discussion). Journal of the Royal Statistical Society B42: 245-292.

Tsay, R. S. 1998. Testing and modeling multivariate threshold models. Journal of the American Statistical Association 84: 231-240.

Tsay, R. S. 2001a. Nonlinear time series models: Testing and applications. In D. Pena; D. C. Tiao; and R. S. Tsay (eds.), A Course in Time Series Analysis. New York: John Wiley \& Sons, Inc.

Tsay, R. S. 2001b. Bayesian time series analysis. In D. Pena; D. C. Tiao; and R. S. Tsay (eds.), A Course in Time Series Analysis. New York: John Wiley Sons, Inc.

Wu, G. 2001. The determinants of asymmetric volatility. Review of Financial Studies 14: 837-859.

Zellner, A. 1971. An Introduction to Bayesian Inference in Econometrics. New York: John Wiley \& Sons. 


\section{Appendix A1. The Procedures of Bayesian Estimation}

The estimation procedures of a Bayesian method are outlined as follows:

a) Write the likelihood function $p(R \mid \Theta)$ as:

$$
\begin{gathered}
p(R \mid \Theta) \propto \prod_{t=2}^{n}\left(2 \pi h_{t}\right)^{-1 / 2} \\
\times \exp \left\{-\frac{1}{2} \sum_{k=1}^{s} \frac{1}{h_{\pi_{k}}}\left[R_{\pi_{k}}^{i}-\phi_{0}^{(1)}-\phi_{1}^{(1)} R_{\pi_{k}-1}^{i}-\psi_{1}^{(1)} R_{\pi_{k}-1}^{j}\right]^{2}\right\} \\
\times \exp \left\{-\frac{1}{2} \sum_{k=s+1}^{n} \frac{1}{h_{\pi_{k}}}\left[R_{\pi_{k}}^{i}-\phi_{0}^{(2)}-\phi_{1}^{(2)} R_{\pi_{k}-1}^{i}-\psi_{1}^{(2)} R_{\pi_{k}-1}^{j}\right]^{2}\right\},
\end{gathered}
$$

where $\Theta=\left(\varphi_{0}^{(1)}, \varphi_{1}^{(1)}, \psi_{1}^{(1)}, \alpha_{0}^{(1)}, \alpha_{1}^{(1)}, \beta_{1}^{(1)}, \varphi_{0}^{(2)}, \varphi_{1}^{(2)}, \psi_{1}^{(2)}, \alpha_{0}^{(2)}, \alpha_{1}^{(2)}, \beta_{1}^{(2)}, r, w, d\right)^{\prime}$;

$R=\left(R_{\pi_{1}}^{i}, R_{\pi_{2}}^{i} \ldots, R_{\pi_{n}}^{i}\right)^{\prime}$; is the time index of the $\mathrm{k}^{\text {th }}$ smallest observation of $z_{1-d}, \ldots$,

$z_{n-d}$; and $s$ satisfies the restriction $z_{\pi_{s}} \leq r<z_{\pi_{s+1}}$.

b) Choose the prior distribution $p(\Theta)$ for $\Theta$ :

$$
\begin{gathered}
p(\Theta) \propto I\left(\alpha_{0}^{(1)}>0, \alpha_{1}^{(1)}+\beta_{1}^{(1)}<1\right) I\left(\alpha_{0}^{(2)}>0, \alpha_{1}^{(2)}+\beta_{1}^{(2)}<1\right) \\
I(a<r<b) I(0 \leq w \leq 1),
\end{gathered}
$$

where $I()$ is the indicator function that $I(A)=1$ if the event $A$ is true, $a$ and $b$ are $25^{\text {th }}$ and $75^{\text {th }}$ percentiles of the threshold variable, $z_{t-d}$, respectively.

(Continued) 


\section{Appendix A1. (Continued)}

c) Obtain the posterior distribution $p(\Theta \mid R)$ by the Bayesian rule:

$$
p(\Theta \mid R) \propto p(R \mid \Theta) p(\Theta) .
$$

d) Sample iteratively from $p(\Theta \mid R)$ to generate a posterior sample $\Theta^{M+1}, \ldots, \Theta^{N}$ by using Markov Chain Monte Carlo methods, where $M=10,000$ is the number of 'burn-in' iterations for convergence and $N=20,000$ is the total number of iterations. The sampling is done in seven blocks:

(i) Sample $\left(\phi_{0}^{(1)}, \phi_{1}^{(1)}, \psi_{1}^{(1)}\right)$ from $p\left(\phi_{0}^{(1)}, \phi_{1}^{(1)}, \psi_{1}^{(1)} \mid R, \Theta_{-\left(\phi_{0}^{(1)}, \phi_{1}^{(1)}, \psi_{1}^{(1)}\right)}\right)$;

(ii) Sample $\left(\alpha_{0}^{(1)}, \alpha_{1}^{(1)}, \beta_{1}^{(1)}\right)$ from $p\left(\alpha_{0}^{(1)}, \alpha_{1}^{(1)}, \beta_{1}^{(1)} \mid R, \Theta_{-\left(\alpha_{0}^{(1)}, \alpha_{1}^{(1)}, \beta_{1}^{(1)}\right)}\right)$;

(iii) Sample $\left(\phi_{0}^{(2)}, \phi_{1}^{(2)}, \psi_{1}^{(2)}\right)$ from $p\left(\phi_{0}^{(2)}, \phi_{1}^{(2)}, \psi_{1}^{(2)} \mid R, \Theta_{-\left(\phi_{0}^{(2)}, \phi_{1}^{(2)}, \psi_{1}^{(1)}\right)}\right)$;

(iv) Sample $\left(\alpha_{0}^{(2)}, \alpha_{1}^{(2)}, \beta_{1}^{(2)}\right)$ from $p\left(\alpha_{0}^{(2)}, \alpha_{1}^{(2)}, \beta_{1}^{(2)} \mid R, \Theta_{-\left(\alpha_{0}^{(2)}, \alpha_{1}^{(2)}, \beta_{1}^{(2)}\right)}\right)$;

(v) Sample $r$ from $p\left(r \mid R, \Theta_{-r}\right)$;

(vi) Sample $w$ from $p\left(w \mid R, \Theta_{-w}\right)$; and

(vii) Sample $d$ from $p\left(d \mid R, \Theta_{-d}\right)$, where $\Theta_{-x}$ represents the vector $\Theta$ without the parameter $x$.

e) Obtain point estimates of the unknown parameters by the sample mean of the posterior sample. The point estimate of $\Theta$, other than $d$, is given by:

$$
\hat{\Theta}=\frac{1}{N-M} \sum_{k=M+1}^{N} \Theta^{k}
$$

f) Estimate $d$ by observing the value occurring most frequently in the posterior sample. 


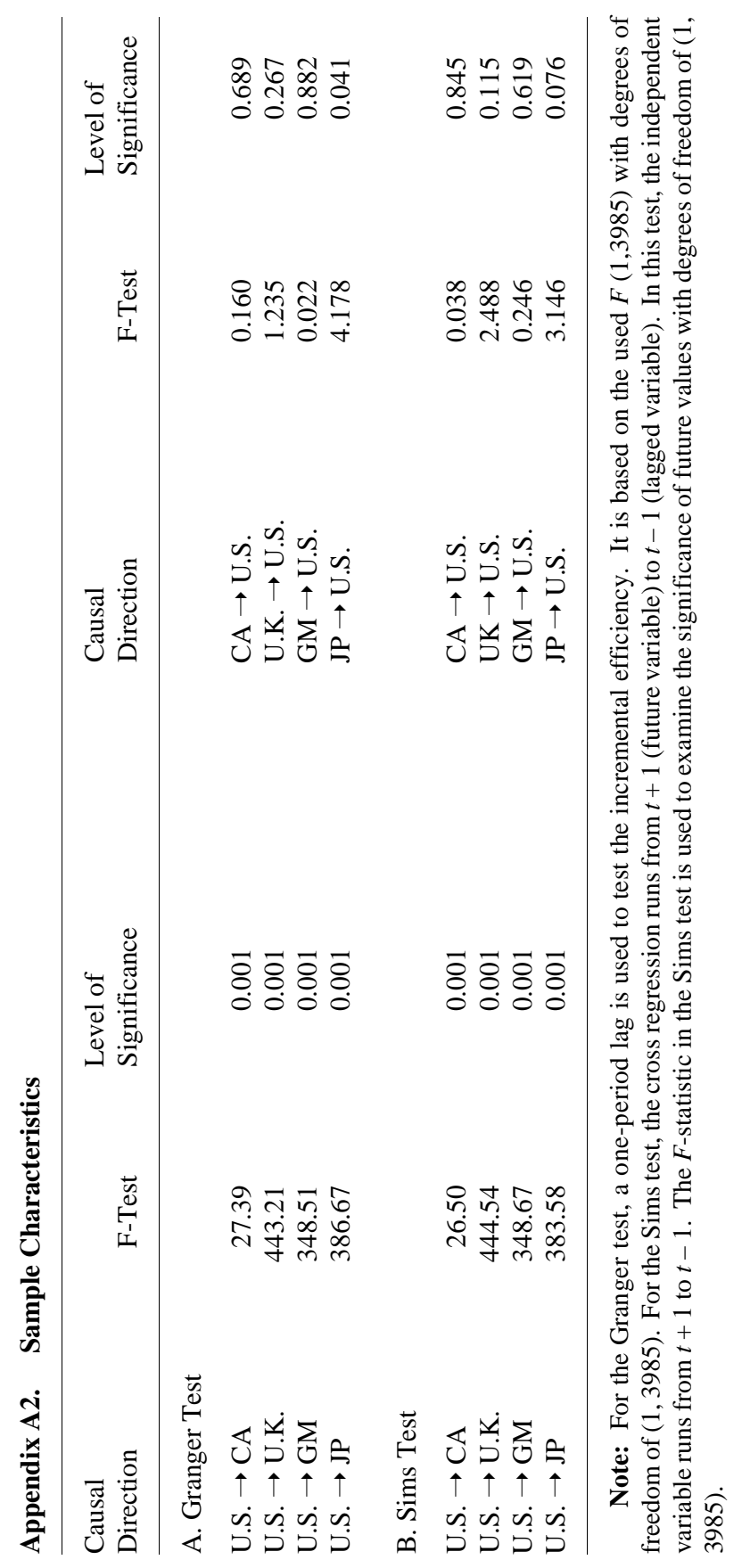

